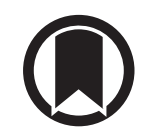

CrossMark

\title{
Targeted therapies: detrimental treatment for nonsmall cell lung cancer without driver mutations
}

\author{
Thierry Berghmans ${ }^{1}$, Anne-Pascale Meert ${ }^{1}$ and Elisabeth Quoix ${ }^{2}$
}

Affiliations: ${ }^{1}$ Dept of Intensive Care and Oncological Emergencies and Thoracic Oncology, Institut Jules Bordet, Centre des tumeurs de l'université Libre de Bruxelles, Brussels, Belgium. ${ }^{2}$ Dept of Pneumology, Hôpitaux Universitaires de Strasbourg, Strasbourg, France.

Correspondence: Thierry Berghmans, Institut Jules Bordet, Rue Héger-Bordet 1, B-1000, Brussels, Belgium. E-mail: thierry.berghmansabordet.be

0 @ERSpublications

Targeted therapies are detrimental in patients with wild-type tumours fit for conventional chemotherapy http://ow.ly/MTgy8

The search for oncogenic driver mutations is currently a standard in the management of advanced nonsquamous nonsmall cell lung cancer (NSCLC) [1], at least for epidermal growth factor receptor $(E G F R)$ activating mutations and anaplastic lymphoma kinase $(A L K)$ rearrangement. At the beginning of the 21st century, two small orally available molecules with EGFR tyrosine kinase inhibitor (TKI) activity, erlotinib and gefitinib, have been developed and tested mainly in unselected Caucasian populations, concomitantly or sequentially with chemotherapy. Five randomised phase III trials did not demonstrate any supplemental activity by adding the TKI to a conventional platinum-based chemotherapy [2-6]. After these disappointing data, additional research showed that these small molecules had a major activity in the presence of EGFR-activating mutations [7, 8]. Multiple randomised trials have now confirmed that first-generation (erlotinib, gefitinib) or second-generation (afatinib) TKIs are more active than platinum-based chemotherapy in terms of response rate and progression-free survival, while their impact on overall survival remains debatable, probably because of the large crossover noted in those trials [9-14].

Conversely, in the absence of driver mutations, EGFR-TKIs are of very limited interest. In a well-designed academic phase III trial [15], 222 patients with EGFR wild-type NSCLC were randomised to receive either salvage erlotinib or docetaxel after failure of first-line platinum-based chemotherapy. All evaluation criteria were inferior for erlotinib: response rate 3\% versus $15.5 \%(\mathrm{p}<0.001)$, median progression-free survival 2.4 versus 2.9 months, and median overall survival 5.4 versus 8.2 months (hazard ratio (HR) 0.73, 95\% CI 0.53 1.00). More data have been generated by another phase III trial (Tarceva or Chemotherapy (TORCH)), which directly compared first-line erlotinib to cisplatin-gemcitabine in 760 patients unselected for their EGFR mutational status [16]. The authors pre-defined a crossover to the opposite regimen at progression. A large statistically significant detrimental effect on survival in the erlotinib arm was noted, with respective median survival times of 8.7 and 11.6 months (HR 1.24, 95\% CI 1.04-1.47).

In the present issue of the European Respiratory Journal, ThOMAs et al. [17] report a phase III trial performed in an unselected Caucasian population comparing frontline therapy with a combination of erlotinib and bevacizumab to a triplet regimen combining cisplatin, gemcitabine and bevacizumab. Notably, there is a biological rationale for adding bevacizumab to erlotinib, as shown in a study of various xenografts of wild-type EGFR or EGFR-TKI-resistant tumour cells [18]. Although, at the molecular level, erlotinib and bevacizumab target different pathways (EGFR and vascular endothelial growth factor (VEGF)), they share both parallel and reciprocal downstream signalling mechanisms. In this study, it was demonstrated that bevacizumab may be useful for enhancing the antitumour activity of erlotinib by

Received: Feb 062015 | Accepted: March 022015

Conflict of interest: Disclosures can be found alongside the online version of this article at erj.ersjournals.com

Copyright @ERS 2015 
increasing the intratumoral concentration of erlotinib in some tumours that express high levels of VEGF protein. These findings justify the trial conducted by Thomas et al. [17].

Except for adding bevacizumab in both arms, the design of the present German study was very similar to the TORCH trial. The results are close, showing a reduced activity of the targeted therapy in comparison with chemotherapy. Response rate ( $12 \%$ versus $36 \% ; \mathrm{p}=0.0001$ ), progression-free survival (median 3.5 versus 6.9 months) and overall survival (median 12.6 versus 17.7 months; $\mathrm{p}=0.0409$ ) all favoured conventional chemotherapy. A retrospective search for EGFR mutational status could be performed in $71 \%$ of the cases, which was representative of the whole population. The activity of erlotinib-bevacizumab in the EGFR-mutant patients, although better than for wild-type tumours, remained disappointing (response rate $25 \%$, median progression-free survival 4.2 months) in comparison to what is generally reported in EGFR-mutated NSCLC. This can be explained by the presence of rare EGFR mutations of indeterminate sensitivity to EGFR-TKI in more than half of the cases, while the statistically nonsignificant increase in overall survival is probably due to the absence of second-line treatment in $75 \%$ of the patients treated with first-line chemotherapy. As a matter of fact, a first-line randomised phase II study with a similar design also did not show a significant advantage for progression-free survival with the combined targeted therapy erlotinib-bevacizumab in comparison to a platinum-based combination plus bevacizumab [19].

It is worthwhile to notice that in the second-line setting, the addition of bevacizumab to erlotinib was compared to erlotinib alone in 636 unselected Caucasian patients with advanced NSCLC. The combination showed no improvement in overall survival, although there was an improvement in progression-free survival and response rate. These two latter objectives were secondary and it was specified that they could only be taken into account if the primary objective (overall survival) was positive, which was not the case [20].

The accessibility of molecular biology in most developed countries and the development of cheaper sensitive techniques allowing determination of EGFR mutational status from small biopsies and cytology do not justify the performance of studies in unselected populations any more. Given the extent of high-quality evidence now published, it seems unethical to propose EGFR-TKIs in patients with wild-type tumours fit for conventional first- and second-line chemotherapy, while their use in an intercalated way with chemotherapy remains in the research domain [21, 22].

\section{References}

1 Lindeman NI, Cagle PT, Beasley MB, et al. Molecular testing guideline for selection of lung cancer patients for EGFR and ALK tyrosine kinase inhibitors: guideline from the College of American Pathologists, International Association for the Study of Lung Cancer, and Association for Molecular Pathology. J Mol Diagn 2013; 15: 415-453.

2 Herbst RS, Giaccone G, Schiller JH, et al. Gefitinib in combination with paclitaxel and carboplatin in advanced non-small-cell lung cancer: a phase III trial - INTACT 2. J Clin Oncol 2004; 22: 785-794.

3 Giaccone G, Herbst RS, Manegold C, et al. Gefitinib in combination with gemcitabine and cisplatin in advanced non-small-cell lung cancer: a phase III trial - INTACT 1. J Clin Oncol 2004; 22: 777-784.

4 Herbst RS, Prager D, Hermann R, et al. TRIBUTE: a phase III trial of erlotinib hydrochloride (OSI-774) combined with carboplatin and paclitaxel chemotherapy in advanced non-small-cell lung cancer. J Clin Oncol 2005; 23: 5892-5899.

5 Gatzemeier U, Pluzanska A, Szczesna A, et al. Phase III study of erlotinib in combination with cisplatin and gemcitabine in advanced non-small-cell lung cancer: the Tarceva Lung Cancer Investigation Trial. J Clin Oncol 2007; 25: 1545-1552.

6 Takeda K, Hida T, Sato T, et al. Randomized phase III trial of platinum-doublet chemotherapy followed by gefitinib compared with continued platinum-doublet chemotherapy in Japanese patients with advanced non-small-cell lung cancer: results of a west Japan thoracic oncology group trial (WJTOG0203). J Clin Oncol 2010; 28: 753-760.

7 Lynch TJ, Bell DW, Sordella R, et al. Activating mutations in the epidermal growth factor receptor underlying responsiveness of non-small-cell lung cancer to gefitinib. N Engl J Med 2004; 350: 2129-2139.

8 Pao W, Miller V, Zakowski M, et al. EGF receptor gene mutations are common in lung cancers from "never smokers" and are associated with sensitivity of tumors to gefitinib and erlotinib. Proc Natl Acad Sci USA 2004; 101: 13306-13311.

9 Sequist LV, Yang JC, Yamamoto N, et al. Phase III study of afatinib or cisplatin plus pemetrexed in patients with metastatic lung adenocarcinoma with EGFR mutations. J Clin Oncol 2013; 31: 3327-3334.

10 Zhou $\mathrm{C}$, Wu YL, Chen G, et al. Erlotinib versus chemotherapy as first-line treatment for patients with advanced EGFR mutation-positive non-small-cell lung cancer (OPTIMAL, CTONG-0802): a multicentre, open-label, randomised, phase 3 study. Lancet Oncol 2011; 12: 735-742.

11 Rosell R, Carcereny E, Gervais R, et al. Erlotinib versus standard chemotherapy as first-line treatment for European patients with advanced EGFR mutation-positive non-small-cell lung cancer (EURTAC): a multicentre, open-label, randomised phase 3 trial. Lancet Oncol 2012; 13: 239-246.

12 Mitsudomi T, Morita S, Yatabe Y, et al. Gefitinib versus cisplatin plus docetaxel in patients with non-small-cell lung cancer harbouring mutations of the epidermal growth factor receptor (WJTOG3405): an open label, randomised phase 3 trial. Lancet Oncol 2010; 11: 121-128.

13 Inoue A, Kobayashi $\mathrm{K}$, Maemondo $\mathrm{M}$, et al. Updated overall survival results from a randomized phase III trial comparing gefitinib with carboplatin-paclitaxel for chemo-naïve non-small cell lung cancer with sensitive EGFR gene mutations (NEJ002). Ann Oncol 2013; 24: 54-59. 
$14 \mathrm{Wu}$ YL, Zhou C, Hu CP, et al. Afatinib versus cisplatin plus gemcitabine for first-line treatment of Asian patients with advanced non-small-cell lung cancer harbouring EGFR mutations (LUX-Lung 6): an open-label, randomised phase 3 trial. Lancet Oncol 2014; 15: 213-222.

15 Garassino MC, Martelli O, Broggini M, et al. Erlotinib versus docetaxel as second-line treatment of patients with advanced non-small-cell lung cancer and wild-type EGFR tumours (TAILOR): a randomised controlled trial. Lancet Oncol 2013; 14: 981-988.

16 Gridelli C, Ciardiello F, Gallo C, et al. First-line erlotinib followed by second-line cisplatin-gemcitabine chemotherapy in advanced non-small-cell lung cancer: the TORCH randomized trial. J Clin Oncol 2012; 30: 3002-3011.

17 Thomas M, Fischer J, Andreas S, et al. Erlotinib and bevacizumab versus cisplatin, gemcitabine and bevacizumab in unselected nonsquamous nonsmall cell lung cancer. Eur Respir J 2015; 46: 219-229.

18 Li H, Takayama K, Wang S, et al. Addition of bevacizumab enhances antitumor activity of erlotinib against non-small cell lung cancer xenografts depending on VEGF expression. Cancer Chemother Pharmacol 2014; 74: $1297-1305$

19 Ciuleanu T, Tsai CM, Tsao CJ, et al. A phase II study of erlotinib in combination with bevacizumab versus chemotherapy plus bevacizumab in the first-line treatment of advanced non-squamous non-small cell lung cancer. Lung Cancer 2013; 82: 276-281.

20 Herbst RS, Ansari R, Bustin F, et al. Efficacy of bevacizumab plus erlotinib versus erlotinib alone in advanced non-small-cell lung cancer after failure of standard first-line chemotherapy (BeTa): a double-blind, placebo-controlled, phase 3 trial. Lancet 2011; 377: 1846-1854.

21 Wu YL, Lee JS, Thongprasert S, et al. Intercalated combination of chemotherapy and erlotinib for patients with advanced stage non-small-cell lung cancer (FASTACT-2): a randomised, double-blind trial. Lancet Oncol 2013; 14: 777-786.

22 Lee DH, Lee JS, Kim SW, et al. Three-arm randomised controlled phase 2 study comparing pemetrexed and erlotinib to either pemetrexed or erlotinib alone as second-line treatment for never-smokers with non-squamous non-small cell lung cancer. Eur J Cancer 2013; 49: 3111-3121. 